\title{
Familiality and Heritability of Fatigue in an Australian Twin Sample
}

\author{
Elizabeth C. Corfield, ${ }^{1}$ Nicholas G. Martin, ${ }^{2}$ and Dale R. Nyholt ${ }^{1}$ \\ ${ }^{1}$ Faculty of Health, Institute of Health and Biomedical Innovation, Queensland University of Technology, Brisbane, QLD, \\ Australia \\ ${ }^{2}$ QIMR Berghofer Medical Research Institute, Brisbane, QLD, Australia
}

\begin{abstract}
Familial factors have previously been implicated in the etiology of fatigue, of which a significant proportion is likely attributable to genetic influences. However, family studies have primarily focused on chronic fatigue syndrome, while univariate twin studies have investigated broader fatigue phenotypes. The results for similar fatigue phenotypes vary between studies, particularly with regard to sex-specific contributions to the heritability of the traits. Therefore, the current study aims to investigate the familiality and sex-specific effects of fatigue experienced over the past few weeks in an older Australian population of 660 monozygotic (MZ) twin pairs, $190 \mathrm{MZ}$ singleton twins, 593 dizygotic (DZ) twin pairs, and $365 \mathrm{DZ}$ singleton twins. Higher risks for fatigue were observed in MZ compared to DZ co-twins of probands with fatigue. Univariate heritability analyses indicated fatigue has a significant genetic component, with a heritability $\left(h^{2}\right)$ estimate of $40 \%$. Sex-specific effects did not significantly contribute to the heritability of fatigue, with similar estimates for males $\left(h^{2}=41 \%, 95 \% \mathrm{Cl}[18,62]\right)$ and females $\left(h^{2}=40 \%, 95 \% \mathrm{Cl}[27,52]\right)$. These results indicate that fatigue experienced over the past few weeks has a familial contribution, with additive genetic factors playing an important role in its etiology.
\end{abstract}

Keywords: fatigue, familiality, heritability, twin study, genetics

Fatigue is a highly prevalent trait with multidimensional symptoms. The broad symptom spectrum is associated with quantifiable difficulties, resulting in fatigue classifications based on arbitrarily defined durations and severities. Commonly utilized classifications include prolonged fatigue, chronic fatigue (CF), idiopathic chronic fatigue (ICF), and chronic fatigue syndrome (CFS). Prolonged fatigue is classified as self-reported persistent or relapsing fatigue experienced for at least one month (Fukuda et al., 1994), and has an estimated population prevalence of 6.16-28.00\%. (Eveng Ård et al., 2005; Hamaguchi et al., 2011; Jason et al., 1999; Kim et al., 2005; Njoku et al., 2007). CF is classified as self-reported persistent or relapsing fatigue experienced for at least six months (Fukuda et al., 1994), and has an estimated population prevalence of 2.00-12.20\% (Bierl et al., 2004; Cho et al., 2009; Eveng Ård et al., 2005; Friedberg et al., 2015; Hamaguchi et al., 2011; Jason et al., 1995, 1999; Kim et al., 2005; Loge et al., 1998; Njoku et al., 2007; Patel et al., 2005; Steele et al., 1998; Wessely et al., 1995, 1997; Wong \& Fielding, 2010). ICF is classified as clinically evaluated, medically unexplained CF, with insufficient symptom presentation for diagnosis with CFS (Fukuda et al., 1994), and has an estimated population prevalence of 1.00-9.00\% (Hamaguchi et al., 2011; Kim et al., 2005; Wessely et al., 1997).

The original CFS classification was published in 1988 by the Centres for Disease Control (Holmes et al., 1988). This CFS classification required the presence of new onset unexplained CF and either six or more symptom criteria (mild fever or chills, sore throat, painful lymph nodes, muscle weakness, muscle discomfort or myalgia, post-exertional fatigue, headaches, migratory arthralgia, neuropsychologic complaints, sleep disturbance, and acute onset) and two physical criteria (low-grade fever, non-exudative pharyngitis, and palpable or tender lymph nodes), or at least eight of the symptom criteria. In 1994, the Centres for Disease Control published a revision to the CFS classification that has become the standard definition utilized worldwide

RECEIVED 1 March 2017; ACCEPTED 23 March 2017

ADDRESS FOR CORRESPONDENCE: Elizabeth C. Corfield, Institute of Health and Biomedical Innovation, Queensland University of Technology, GPO Box 2434, Brisbane, QLD 4001, Australia. E-mail: elizabeth.corfield@connect.qut.edu.au 
(Fukuda et al., 1994). The 1994 CFS classification requires clinically evaluated, medically unexplained CF, with four or more physical symptoms (sore throat, tender lymph nodes, headaches, cognitive difficulties, unrefreshing sleep, multijoint pain, muscle pain, and post-exertional malaise) experienced over a 6-month period that have not pre-dated the fatigue (Fukuda et al., 1994). The population prevalence of CFS has been estimated at 0.07-2.60\% (Cho et al., 2009; Hamaguchi et al., 2011; Jason et al., 1999; Kawakami et al., 1998; Kim et al., 2005; Lindal et al., 2002; Nacul et al., 2011; Njoku et al., 2007; Reyes et al., 2003; Vincent et al., 2012; Wessely et al., 1995, 1997).

Familial studies of fatigue have mainly focused on CFS. In 1991, Bell et al. (1991) showed that children (aged 617) with CFS (based on the original CFS classification) were significantly more likely to have family members with CFS symptoms than asymptomatic controls (relative risks [RR] $=48.60,95 \%$ CI $[9.43,587.22]$ ), although the degree of relatedness investigated by the authors is unclear. In 2001, Walsh et al. (2001) showed that first-degree relatives of CFS cases (with a mean age of 37.6 years) have an increased risk of prolonged fatigue $(\mathrm{RR}=2.18,95 \% \mathrm{CI}[0.88,3.48])$ and CFS ( $\mathrm{RR}=9.22$, 95\% CI [7.84, 10.60]). Additionally, Buchwald et al. (2001) showed that monozygotic (MZ) twin pairs have higher concordance rates compared to dizygotic (DZ) twin pairs for CF and ICF (within a cohort with a mean age of 46 years). In 2006, adolescents, aged 12-18, with CFS and their mothers were shown to have shared symptom complexes that were not exhibited by their fathers (van de Putte et al., 2006). Finally, in 2011, Albright et al. (2011) showed that CFS cases' first- (RR $=2.70,95 \% \mathrm{CI}$ $[1.56,4.66])$, second- $(\mathrm{RR}=2.34,95 \% \mathrm{CI}[1.32,4.19])$, and third- degree relatives $(\mathrm{RR}=1.93,95 \% \mathrm{CI}[1.21,3.07])$ had an increased risk of CFS compared to controls. These family studies indicate genetic and common environmental factors likely contribute to CFS.

Univariate twin studies have been utilized to estimate the contribution of additive genetic (also known as narrow-sense heritability $\left.\left[h^{2}\right]\right)$, common environmental, and unique environmental factors to the variation observed in the population of interfering fatigue (tiredness or fatigue experienced for at least five days), abnormal tiredness, prolonged fatigue, CF, ICF, and CFS, in adults (see Table 1 for a summary) (Buchwald et al., 2001; Schur et al., 2007; Sullivan et al., 2003, 2005). Interfering fatigue has an estimated genetic heritability of $6 \%$ in males and $26 \%$ in females (Sullivan et al., 2003). Similarly, abnormal tiredness has an estimated genetic heritability of $30 \%$ in males and $26 \%$ in females (Sullivan et al., 2005). Prolonged fatigue has an estimated genetic heritability of $34-51 \%$ in males and $18-27 \%$ in females (Schur et al., 2007; Sullivan et al., 2005). CF has an estimated genetic heritability of $30-47 \%$ in males and $12-32 \%$ in females (Buchwald et al., 2001; Schur et al., 2007; Sullivan et al., 2005). Finally, ICF and CFS both have an estimated genetic heritability of $51 \%$ in females (Buchwald et al., 2001; Schur et al., 2007). Notably, the heritability estimates for males and females were similar within the Swedish cohort, which had an age range of 4264 years. Meanwhile, the American cohorts with mean ages of 32.4 years and approximately 35 years have greater differences in genetic heritability estimates between the sexes.

To date, only two studies have been conducted that included children or adolescents and utilized univariate twin modeling to investigate the contribution of genetic and environmental factors in fatigue phenotypes. The first study investigated the heritability of short-duration fatigue (fatigue experienced for at least one week) and prolonged fatigue within children (aged 5-17) from South Wales (Farmer et al., 1999). However, sex-specific effects were not investigated and confidence intervals were not reported for the heritability estimates. Nonetheless, short-duration fatigue had an estimated additive genetic, common environmental, and unique environmental contribution of $42 \%$, $38 \%$, and $20 \%$, respectively. Similarly, prolonged fatigue had an estimated additive genetic, common environmental, and unique environmental contribution of $54 \%, 19 \%$, and $26 \%$, respectively. Meanwhile, the heritability of fatigue severity (a continuous scale of the 11 core fatigue items and 2 muscle pain items of the Chalder Fatigue Questionnaire; Chalder et al., 1993) and abnormal fatigue (assessed by the 11 core fatigue items of the Chalder Fatigue Questionnaire) was investigated in a Sri Lankan population of adolescents and adults (aged $\geq 15$; Ball et al., 2010). Fatigue severity had an estimated additive genetic and unique environmental contribution of $30 \%$ (95\% CI $[24,35])$ and $70 \%$ (95\% CI [65, $76]$ ), respectively. Similarly, abnormal fatigue had an estimated additive genetic and unique environmental contribution of $39 \%$ (95\% CI $[29,49])$ and $61 \%(95 \%$ CI $[51,71])$, respectively.

Additional studies have utilized multivariate twin modeling to investigate the contribution of shared genetic and environmental factors to numerous traits that are comorbid or hypothesized to be associated with fatigue. The traits investigated within previous multivariate studies include various fatigue definitions (i.e., fatigue symptoms, shortduration fatigue, abnormal fatigue, fatigue, prolonged fatigue, and CF) and major depressive disorder, insomnia, psychological distress, anxiety, depression, psychological symptoms, somatic symptoms, generalized anxiety disorder, disability pension due to neurotic diagnoses, headaches, irritable bowel syndrome, chronic widespread pain, immune responsiveness, and the immunological factors IL-4, IFN- $\gamma$, and sCD23. The heritability of the various fatigue measures ranged from $7 \%$ to $60 \%$, and a number of these studies reported significant evidence for shared genetic factors between fatigue and other traits; in particular, strong genetic correlations $\left(r_{\mathrm{g}}\right)$ were observed between prolonged fatigue and depression $\left(r_{\mathrm{g}}=0.53\right), \mathrm{CF}$ and depression or anxiety $\left(r_{\mathrm{g}}=0.60\right)$, fatigue and psychological distress $\left(r_{\mathrm{g}}=0.67\right)$, and fatigue and immune responsiveness 


\section{TABLE 1}

Previously Published Variance Estimates (With Their 95\% Confidence Intervals) for Varying Fatigue Classifications, in Adults, From Univariate Structural Equation Modeling

\begin{tabular}{|c|c|c|c|c|c|c|c|c|c|c|}
\hline \multirow[b]{2}{*}{ Fatigue classification } & \multirow[b]{2}{*}{ Study } & \multirow[b]{2}{*}{ Population } & \multirow{2}{*}{$\begin{array}{l}\text { Mean age } \pm \text { standard } \\
\text { deviation (age range) }\end{array}$} & \multirow{2}{*}{$\begin{array}{l}\text { Number of } \\
\text { twin pairs }\end{array}$} & \multicolumn{3}{|c|}{ Male (M) } & \multicolumn{3}{|c|}{ Female (F) } \\
\hline & & & & & A & C & E & A & C & $\mathrm{E}$ \\
\hline Interfering fatigue & Sullivan et al. (2003) & United States & $\begin{array}{l}\text { Case: } 34.9 \pm 9.3 \\
\text { Control: } 35.1 \pm 9.2\end{array}$ & $\begin{array}{l}M=3,422 \\
F=3,104\end{array}$ & $\begin{array}{l}0.06 \\
{[0.00,0.46]}\end{array}$ & $\begin{array}{l}0.21 \\
{[0.00,0.25]}\end{array}$ & $\begin{array}{l}0.73 \\
{[0.54,0.90]}\end{array}$ & $\begin{array}{l}0.26 \\
{[0.00,0.44]}\end{array}$ & $\begin{array}{l}0.01 \\
{[0.00,0.30]}\end{array}$ & $\begin{array}{l}0.73 \\
{[0.56,0.92]}\end{array}$ \\
\hline Abnormal tiredness & Sullivan et al. (2005) & Swedish & $(42-64)$ & $\begin{array}{l}M=11,293 \\
F=12813\end{array}$ & 0.30 & $\begin{array}{l}0.00 \\
{[0.00 \quad 0.14]}\end{array}$ & $\begin{array}{l}0.70 \\
0.60 \quad 0.801\end{array}$ & $\left.\begin{array}{ll}0.26 & \\
0.08 & 0.33\end{array}\right]$ & $\begin{array}{l}0.00 \\
10.00 \quad 0.14]\end{array}$ & $\begin{array}{l}0.74 \\
{[0.67 \quad 0.82]}\end{array}$ \\
\hline \multirow[t]{2}{*}{ Prolonged fatigue } & Sullivan et al. (2005) & Swedish & $(42-64)$ & $\begin{array}{l}M=11,293 \\
F=12,813\end{array}$ & $\begin{array}{l}0.34 \\
{[0.03,0.45]}\end{array}$ & $\begin{array}{l}0.00 \\
{[0.00,0.25]}\end{array}$ & $\begin{array}{l}0.66 \\
{[0.55,0.79]}\end{array}$ & $\begin{array}{l}0.27 \\
{[0.06,0.35]}\end{array}$ & $\begin{array}{l}0.00 \\
{[0.00,0.16]}\end{array}$ & $\begin{array}{l}0.73 \\
{[0.65,0.82]}\end{array}$ \\
\hline & Schur et al. (2007) & United States & $\begin{array}{l}32.4 \pm 14.7 \\
(18-90)\end{array}$ & $\begin{array}{l}M=1,468 \\
F=2,272\end{array}$ & $\begin{array}{l}0.51 \\
{[0.13,0.69]}\end{array}$ & $\begin{array}{l}0.00 \\
{[0.00,0.33]}\end{array}$ & $\begin{array}{l}0.49 \\
{[0.31,0.71]}\end{array}$ & $\begin{array}{l}0.18 \\
{[0.00,0.54]}\end{array}$ & $\begin{array}{l}0.23 \\
{[0.00,0.48]}\end{array}$ & $\begin{array}{l}0.59 \\
{[0.46,0.74]}\end{array}$ \\
\hline \multirow[t]{3}{*}{ Chronic fatigue } & Buchwald et al. (2001) & United States & 46 & $F=146$ & - & - & - & $\begin{array}{l}0.19 \\
{[0.00,0.56]}\end{array}$ & $\begin{array}{l}0.69 \\
{[0.32,0.89]}\end{array}$ & $\begin{array}{l}0.12 \\
{[0.07,0.19]}\end{array}$ \\
\hline & Sullivan et al. (2005) & Swedish & $(42-64)$ & $\begin{array}{l}M=11,293 \\
F=12,813\end{array}$ & $\begin{array}{l}0.30 \\
{[0.02,0.44]}\end{array}$ & $\begin{array}{l}0.00 \\
{[0.00,0.23]}\end{array}$ & $\begin{array}{l}0.70 \\
{[0.56,0.86]}\end{array}$ & $\begin{array}{l}0.32 \\
{[0.11,0.41]}\end{array}$ & $\begin{array}{l}0.00 \\
{[0.00,0.16]}\end{array}$ & $\begin{array}{l}0.68 \\
{[0.59,0.78]}\end{array}$ \\
\hline & Schur et al. (2007) & United States & $\begin{array}{l}32.4 \pm 14.7 \\
(18-90)\end{array}$ & $\begin{array}{l}M=1,468 \\
F=2,272\end{array}$ & $\begin{array}{l}0.47 \\
{[0.00,0.68]}\end{array}$ & $\begin{array}{l}0.00 \\
{[0.00,0.39]}\end{array}$ & $\begin{array}{l}0.53 \\
{[0.32,0.79]}\end{array}$ & $\begin{array}{l}0.12 \\
{[0.00,0.48]}\end{array}$ & $\begin{array}{l}0.26 \\
{[0.00,0.48]}\end{array}$ & $\begin{array}{l}0.62 \\
{[0.47,0.78]}\end{array}$ \\
\hline $\begin{array}{l}\text { Idiopathic chronic } \\
\text { fatigue }\end{array}$ & Buchwald et al. (2001) & United States & 46 & $F=146$ & - & - & - & 0.51 & 0.42 & 0.08 \\
\hline $\begin{array}{l}\text { Chronic fatigue } \\
\text { syndrome }\end{array}$ & Schur et al. (2007) & United States & $\begin{array}{l}32.4 \pm 14.7 \\
(18-90)\end{array}$ & $\begin{array}{l}M=1,444 \\
F=2,222\end{array}$ & - & - & - & $\begin{array}{c}{[0.07,0.96]} \\
0.51 \\
{[0.00,0.82]}\end{array}$ & $\begin{array}{l}{[0.00,0.85]} \\
0.12 \\
{[0.00,0.72]}\end{array}$ & $\begin{array}{c}{[0.04,0.13]} \\
0.36 \\
{[0.18,0.65]}\end{array}$ \\
\hline
\end{tabular}

Note: $\mathrm{A}$ = additive genetic component, $\mathrm{C}=$ common environmental component, $\mathrm{E}=$ unique environmental component. 
$\left(r_{\mathrm{g}}=0.76\right)$ (Ball et al., 2011; Fowler et al., 2006; Hickie, Bennett et al., 1999; Hickie, Kirk et al., 1999; Hickie et al., 2001; Hur et al., 2012; Kato et al., 2009; Narusyte et al., 2016).

Given the large variation in both the definition of fatigue and estimates of heritability produced from a relatively small number of univariate twin studies (conducted in Swedish and American cohorts), the current study aimed to investigate the heritability of fatigue experienced over the past few weeks in a cohort of Australian twin pairs. While previously published family studies have focused on CFS, we assessed the familiality of fatigue experienced over a shorter time period.

\section{Materials and Methods}

\section{Study Cohort and Fatigue Classification}

The present study utilized data from the over 50's (aged) study conducted by the genetic epidemiology group within the QIMR Berghofer Medical Research Institute (QIMRB), between 1993 and 1996. The study invited 2,281 twin pairs, aged over 50, from the Australian Twin Registry to complete a 16-page mailed Health and Lifestyle Questionnaire (Bucholz et al., 1998; Mosing et al., 2012). Informed written consent was obtained from each participant, and the study was approved by the Human Research Ethics Committee (HREC) of QIMRB.

The fatigue classification utilized throughout this study was assessed by the Schedule of Fatigue and Anergia (SOFA; Hickie et al., 1996). Ten questions are contained in the SOFA; however, a shorter eight-item version was used in the Health and Lifestyle Questionnaire, due to two items being replicated within the General Health Questionnaire (GHQ; Goldberg \& Blackwell, 1970) that was also administered to the participants. Responses to the eight SOFA and two GHQ items were used to assess fatigue within the cohort, as previously detailed (Corfield et al., 2016). Individuals were classified as fatigued if they reported three or more of the 10 fatigue symptoms (muscle pain at rest, post-exertional muscle pain, post-exertional muscle fatigue, post-exertional fatigue, hypersomnia, insomnia, poor concentration, speech problems, poor memory, and headaches) over the past few weeks.

\section{Statistical Analysis}

Familial clustering of fatigue was investigated by calculating $\mathrm{RR}$, measured by the prevalence ratio, with their $95 \% \mathrm{CI}$ in complete $\mathrm{MZ}$ and $\mathrm{DZ}$ twin pairs. RR were calculated relative to non-fatigued individuals. Within $\mathrm{MZ}$ and same-sex DZ twin pairs, RR were calculated by averaging over using twin 1 or twin 2 as the proband.

Tetrachoric correlations were calculated for fatigue within $\mathrm{MZ}$ and $\mathrm{DZ}$ twin pairs and singleton twins using the polycor package in $\mathrm{R}$ ( $\mathrm{R}$ Core Team, 2014). The tetrachoric correlation assumes that underlying the observed binary distribution of affection status, there exists a con- tinuous, normally distributed latent (non-observable) liability (Kendler, 1993). That is, the tetrachoric correlation is an estimate of the correlation between two latent variables, where each latent variable is assumed to have a bivariate normal distribution. Comparison of the correlations between $\mathrm{MZ}$ and $\mathrm{DZ}$ twins was used to provide information on the importance of genetic and environmental factors contributing to the heritability of fatigue. Correlations that are larger in $\mathrm{MZ}$ compared to $\mathrm{DZ}$ twins indicate that the phenotype has a genetic contribution, while correlations that are similar in MZ and DZ twins indicate that the environmental factors explain the majority of variation in the phenotype.

Structural equation modeling (SEM), including the threshold model, was utilized to investigate the heritability of fatigue. The threshold model posits that distinct traits represent a single, normally distributed, severity continuum. A single threshold was used to separate non-fatigued and fatigued individuals. SEM was used to estimate the contribution of additive genetic (A), non-additive (dominance) genetic (D), common environmental (C), and unique environmental (E) variance components (Neale \& Cardon, 1992). Adjustments for (linear) age and sex effects were included in the model. Significance of the variance components was assessed by comparing the fit of the full model ( $\mathrm{ACE} / \mathrm{ADE}$ ) to the nested models (AE, $\mathrm{CE}$, and $\mathrm{E}$ ) where the effect was dropped, using OpenMx in R (Boker et al., 2011). Additionally, sex-limitation modeling was conducted to determine whether sex-specific effects contribute to the heritability of fatigue. Initially, a non-scalar sex-limitation model was fitted that included variance components for females (i.e., Af, Cf, and Ef) and males (i.e., Am, Cm, and Em), as well as an additional additive genetic component specific to males ( $\left.A^{\prime} m\right)$. Restricted non-scalar sexlimitation modeling was then conducted, whereby $A^{\prime}$ m was removed. The goodness-of-fit parameters used to assess the differences in the twin models were the likelihood-ratio chi-square test $\left(\chi^{2}\right)$ and the $p$ value. Additionally, model fit was compared utilizing Akaike's Information Criteria (AIC), with the lowest AIC indicating the most parsimonious model (Akaike, 1973, 1974).

Tetrachoric correlations and SEM were estimated using full information maximum likelihood (FIML), whereby both complete twin pairs and incomplete twin pairs (singleton twins) were included in the analyses. The inclusion of singleton twins provides more accurate estimation of the thresholds and may correct for participation bias.

\section{Results}

Within the over 50's study, 473 twin pairs and 555 singleton twins returned incomplete responses to the SOFA and GHQ questionnaire items utilized to assess fatigue within the present study and were therefore excluded. The remaining 1,253 complete twin pairs and 555 singleton twins with 


\section{TABLE 2}

Relative Risk a of Fatigue Within Complete Monozygotic (MZ), Same-Sex Dizygotic $\left(D Z_{s s}\right)$, and Opposite-Sex Dizygotic $\left(D Z_{o s}\right)$ Twin Pairs

\begin{tabular}{|c|c|c|}
\hline Zygosity & $\begin{array}{c}\text { Number of complete } \\
\text { twin pairs }\end{array}$ & $\mathrm{RR}(95 \% \mathrm{Cl})$ \\
\hline $\mathrm{MZ}$ & 660 & $2.20[1.77,2.75]$ \\
\hline $\mathrm{MZ}[\mathrm{F}-\mathrm{F}]$ & 504 & $2.14[1.68,2.74]$ \\
\hline $\mathrm{MZ}[\mathrm{M}-\mathrm{M}]$ & 156 & $2.28[1.38,3.78]$ \\
\hline DZ total & 593 & $1.32[1.01,1.73]$ \\
\hline$D Z_{\text {ss }}$ & 348 & $1.16[0.83,1.62]$ \\
\hline $\mathrm{DZ}_{\mathrm{ss}}[\mathrm{F}-\mathrm{F}]$ & 272 & $1.14[0.78,1.66]$ \\
\hline$D Z_{s s}[M-M]$ & 76 & $1.23[0.61,2.49]$ \\
\hline $\mathrm{DZ}_{\text {os }}$ & 241 & $1.59[1.03,2.45]$ \\
\hline \multicolumn{3}{|c|}{$\begin{array}{l}\text { Note: } \mathrm{F}=\text { female, } \mathrm{M}=\text { male. } \\
\text { aRelative risks and } 95 \% \text { confidence intervals }(\mathrm{Cl}) \text { were calculated with } \\
\text { respect to non-depressed or non-fatigued status in twin } 1 \text {. Same-sex } \\
\text { twin pair tables were made symmetrical by averaging over using twin } \\
1 \text { or twin } 2 \text { as the proband. }\end{array}$} \\
\hline
\end{tabular}

\section{TABLE 3}

Tetrachoric Correlations ( $r$ ) With Their $95 \%$ Confidence Intervals (Cl) for Fatigue According to Zygosity

\begin{tabular}{lc}
\hline Zygosity & $r(95 \% \mathrm{Cl})$ \\
\hline $\mathrm{MZ}$ & $0.43[0.32,0.54]$ \\
$\mathrm{MZ}[\mathrm{F}-\mathrm{F}]$ & $0.43[0.30,0.56]$ \\
$\mathrm{MZ}[\mathrm{M}-\mathrm{M}]$ & $0.41[0.17,0.66]$ \\
$\mathrm{DZ}$ total & $0.14[0.01,0.28]$ \\
$\mathrm{DZ}_{\text {ss }}$ & $0.08[-0.10,0.26]$ \\
$\mathrm{DZ}_{\text {ss }}[\mathrm{F}-\mathrm{F}]$ & $0.07[-0.14,0.27]$ \\
$\mathrm{DZ}_{\text {ss }}[\mathrm{M}-\mathrm{M}]$ & $0.12[-0.26,0.51]$ \\
$\mathrm{DZ}_{\text {os }}$ & $0.24[0.02,0.46]$ \\
\hline Note: $\mathrm{F}=$ female, $\mathrm{M}=$ male. &
\end{tabular}

fatigue data comprised the cohort utilized within the present study. The study cohort contained $660 \mathrm{MZ}$ twin pairs (504 female-female and 156 male-male twin pairs) and $190 \mathrm{MZ}$ singleton twins (109 females and 81 males) with a mean age of $61.3 \pm 8.9$ (range $=50-92$ ), and $593 \mathrm{DZ}$ twin pairs (272 female-female, 76 male-male, 137 femalemale, and 108 male-female twin pairs) and $365 \mathrm{DZ}$ singleton twins (260 females and 105 males) with a mean age of $61.0 \pm 8.5$ (range $=50-94$ ). The prevalence of fatigue defined as above was $30.7 \%$ (31.7\% of females and $28.3 \%$ of males).

An increased risk of fatigue in co-twins of fatigued probands was observed, indicating a significant familial contribution. Strong evidence for a genetic contribution to fatigue is provided by the higher RR observed in MZ compared to DZ twin pairs (Table 2). In particular, the risk of fatigue in co-twins of fatigued probands was 2.20 (95\% CI $[1.77,2.75])$ in $\mathrm{MZ}$ twin pairs compared to 1.32 (95\% CI $[1.01,1.73])$ in DZ twin pairs (applicable to first-degree relatives in the general population). Analysis of familial clustering within males and females indicated a similar pattern of risks.

The tetrachoric correlations for fatigue were approximately three times larger in $\mathrm{MZ}$ compared to $\mathrm{DZ}$ twin pairs (Table 3). Overall, the observed MZ > DZ correlations indi- cate that additive genetic factors contribute to the variation in fatigue.

Initially, full univariate $\mathrm{ACE}$ and $\mathrm{ADE}$ models were fitted; however, systematic dropping of A, C, and D effects was used to determine whether the effect of the individual variance components were significant (Table 4). Dropping $\mathrm{C}$ (i.e., AE model) from the ACE model did not worsen the model fit. However, dropping A (i.e., CE model) or both A and $C$ (i.e., $\mathrm{E}$ model) was significant $\left(p=4.76 \times 10^{-3}\right.$ and $8.91 \times 10^{-11}$, respectively)-indicating $\mathrm{A}$ is an important source of variance in the heritability of fatigue. Meanwhile, dropping D (i.e., AE model), from the ADE model, did not worsen the model fit. However, dropping both $\mathrm{A}$ and $\mathrm{D}$ (i.e., E model) was significant $\left(p=6.46 \times 10^{-11}\right)$-indicating genetic factors play an essential role in the heritability of fatigue. Therefore, the AE model was selected as the most parsimonious model based on fit statistics. No differences in threshold distributions were observed within twin pairs and singleton twins, or across zygosity and sex groups.

Additive genetic factors were estimated to explain approximately $40 \%$ of the heritability of fatigue. No significant evidence for sex-specific genetic effects was observed within the cohort. The results of the non-scalar sexlimitation modeling indicated that the restricted model was the most parsimonious ( $\mathrm{AIC}=-2405.41$ ) with similar heritability estimates for fatigue in males, at $41 \%$ ( $95 \%$ CI [ 18 , $62] ; E=59 \%, 95 \% \mathrm{CI}[38,82])$, compared to females, at $40 \%$ (95\% CI $[27,52] ; E=60 \%, 95 \%$ CI $[48,73])$.

\section{Discussion}

The findings from the present study indicate that fatigue in older adults is familial and has a genetic contribution with no significant sex-specific effects.

The familial clustering analysis revealed that co-twins of fatigued probands were at an increased risk of fatigue. These results indicate that the familial contribution of fatigue is not specific to CFS, although in 2001 the first-degree relatives of CFS cases were shown to have an increased risk of prolonged fatigue and MZ twin pairs were shown to have higher concordance rates than $\mathrm{DZ}$ twin pairs for $\mathrm{CF}$ and ICF (Buchwald et al., 2001; Walsh et al., 2001). However, to our knowledge, this is the first study to characterize the familial clustering of fatigue experienced for less than 6 months. The higher risk observed in MZ twin pairs compared to DZ twin pairs indicates genetic factors likely contribute to the etiology of fatigue. These results are reflective of the conclusions drawn from previous family studies of CF, ICF, and CFS (Buchwald et al., 2001; van de Putte et al., 2006). However, the similar pattern of risks observed within males and females indicates that the underlying etiology of fatigue is likely independent of sex. This finding opposes the results of van de Putte et al. (2006), who found an increase of CFS symptoms in mothers of children with CFS, 
TABLE 4

Fit Statistics and Variance Estimates (With Their 95\% Confidence Intervals) From Univariate Structural Equation Modeling

\begin{tabular}{|c|c|c|c|c|c|c|c|}
\hline Model & $-2 \mathrm{LL}$ & $p$ value (ACE) & $p$ value (ADE) & AIC & A & $C$ (or D) & $\mathrm{E}$ \\
\hline ACE & 3704.60 & NA & NA & -2407.40 & $\begin{array}{l}0.40 \\
{[0.15,0.50]}\end{array}$ & $\begin{array}{l}0.00 \\
{[0.00,0.20]}\end{array}$ & $\begin{array}{l}0.60 \\
{[0.50,0.71]}\end{array}$ \\
\hline$A D E$ & 3703.96 & NA & NA & -2408.05 & $\begin{array}{l}0.17 \\
{[0.00,0.50]}\end{array}$ & $\begin{array}{l}0.25 \\
{[0.00,0.53]}\end{array}$ & $\begin{array}{l}0.58 \\
{[0.47,0.70]}\end{array}$ \\
\hline $\mathrm{AE}$ & 3704.60 & 1.00 & 0.42 & -2409.40 & $\begin{array}{l}0.40 \\
{[0.29,0.50]}\end{array}$ & - & $\begin{array}{l}0.60 \\
{[0.50,0.71]}\end{array}$ \\
\hline CE & 3712.57 & $4.76 \times 10^{-3}$ & NA & -2401.43 & - & $\begin{array}{l}0.30 \\
{[0.21,0.39]}\end{array}$ & $\begin{array}{l}0.71 \\
{[0.61,0.79]}\end{array}$ \\
\hline$E$ & 3750.88 & $8.91 \times 10^{-11}$ & $6.46 \times 10^{-11}$ & -2365.12 & - & - & $\begin{array}{l}1.00 \\
{[1.00,1.00]}\end{array}$ \\
\hline
\end{tabular}

Note: $-2 \mathrm{LL}=$ minus two log-likelihood, $\mathrm{A}=$ additive genetic component, $\mathrm{C}=$ common environmental component, $\mathrm{E}=$ unique environmental component. The best-fitting model is indicated in bold. $p$ value compares $-2 L L$ for the full ACE or ADE model to the reduced (AE, CE, $D E$, and $E)$ models.

but not fathers. Indicating the etiology of fatigue may differ with age.

The differences in genetic heritability between males and females identified within previous twin studies are larger in the cohorts comprised of younger adults compared to cohorts of older cohorts. In contrast, results from the present study indicate that the underlying etiology of fatigue is independent of sex in older adults. Sex-limitation modeling revealed males $\left(h^{2}=41 \%, 95 \%\right.$ CI $\left.[18,62]\right)$ and females $\left(h^{2}=40 \%\right.$ (95\% CI $\left.[27,52]\right)$ had very similar heritability estimates. Furthermore, based on fit statistics, the most parsimonious model was the univariate AE twin model, which did not include sex-specific effects. These results support the suggestion of Sullivan et al. (2005) that females and males have similar genetic and environmental contributions for varying fatigue classifications, despite the higher prevalence of fatigue in females. In comparison, Schur et al. (2007) suggested that further investigations are required to understand the differences in fatigue etiology between the sexes. Based on our results and previous findings, we suggest that a further investigation into the heritability of fatigue across the lifespan is required.

A possible limitation of our study is the utilization of self-report rather than interview-based data. However, considering prolonged fatigue and CF classifications are based on self-report, the utilization of questionnaire-based data is valid. Additionally, this prevented confounding within the study by healthcare-seeking behavior, due to the population-based structure of the cohort. Another potential limitation of the study was the utilization of a nonstandard fatigue duration due to the ambiguity of the questionnaire, which assessed fatigue symptoms experienced 'over the past few weeks'. However, considering the SOFA was designed to assess CFS symptoms, fatigue is representative of a spectrum, and previous studies have looked at similar fatigue definitions-our findings still offer valid insights into the underlying etiology of fatigue.

In summary, we have shown that fatigue experienced over the past few weeks is familial, with additive genetic factors explaining a substantial proportion of its variance in older adults. Future research aimed at identifying the specific genes and risk loci associated with fatigue (e.g., via genome-wide association studies), will increase our understanding of its underlying biological mechanisms.

\section{Acknowledgements}

We would like to thank the twins for their cooperation and study staff for data collection. Mr. George Landers', of Chania, Crete, generous donations funded this research. Elizabeth C. Corfield was supported by an Australian Postgraduate Award (APA) from the Australian Government. Dale R. Nyholt was supported by an Australian National Health and Medical Research Council (NHMRC) Research Fellowship (Application ID 613674).

\section{Disclosure of Interests}

None.

\section{Details of Ethical Approval}

Informed written consent was obtained from each participant, and the study was approved by the Human Research Ethics Committee (HREC) of the QIMR Berghofer Medical Research Institute (QIMRB).

\section{References}

Akaike, H. (1973, September). Information theory and an extension of the maximum likelihood principle. Paper presented at the second international symposium on information theory, Tsahkadsor, Armenia, USSR.

Akaike, H. (1974). A new look at the statistical model identification. IEEE Transactions on Automatic Control, 19, 716723.

Albright, F., Light, K., Light, A., Bateman, L., \& CannonAlbright, L. A. (2011). Evidence for a heritable predisposition to chronic fatigue syndrome. BMC Neurology, 11, 6267.

Ball, H. A., Siribaddana, S. H., Sumathipala, A., Kovas, Y., Glozier, N., Rijsdijk, F., ... Hotopf, M. (2011). Genetic and environmental contributions to the overlap between psychological, fatigue and somatic symptoms: A twin study in Sri Lanka. Twin Research and Human Genetics, 14, 53-63. 
Ball, H. A., Sumathipala, A., Siribaddana, S. H., Kovas, Y., Glozier, N., McGuffin, P., \& Hotopf, M. (2010). Aetiology of fatigue in Sri Lanka and its overlap with depression. British Journal of Psychiatry, 197, 106-113.

Bell, K. M., Cookfair, D., Bell, D. S., Reese, P., \& Cooper, L. (1991). Risk factors associated with chronic fatigue syndrome in a cluster of pediatric cases. Reviews of Infectious Diseases, 13, S32-S38.

Bierl, C., Nisenbaum, R., Hoaglin, D. C., Randall, B., Jones, A. B., Unger, E. R., \& Reeves, W. C. (2004). Regional distribution of fatiguing illnesses in the United States: A pilot study. Population Health Metrics, 2, 1-7.

Boker, S., Neale, M., Maes, H., Wilde, M., Spiegel, M., Brick, T., ... Fox, J. (2011). OpenMx: An open source extended structural equation modeling framework. Psychometrika, 76, 306-317.

Bucholz, K. K., Heath, A. C., Madden, P. A. F., Slutske, W. S., Statham, D. J., Dunne, M. P., \& Martin, N. G. (1998). Drinking in an older population: Cross-sectional and longitudinal data from the Australian twin registry. In E. L. Gomberg, A. M. Hegedus, \& R. A. Zucker (Eds.), Alcohol problems and aging (pp. 41-62). Bethesda, MD: National Institutes of Health.

Buchwald, D., Herrell, R., Ashton, S., Belcourt, M., Schmaling, K., Sullivan, P., ... Goldberg, J. (2001). A twin study of chronic fatigue. Psychosomatic Medicine, 63, 936-943.

Chalder, T., Berelowitz, G., Pawlikowska, T., Watts, L., Wessely, S., Wright, D., \& Wallace, E. P. (1993). Development of a fatigue scale. Journal of Psychosomatic Research, 37, 147153.

Cho, H. J., Menezes, P. R., Hotopf, M., Bhugra, D., \& Wessely, S. (2009). Comparative epidemiology of chronic fatigue syndrome in Brazilian and British primary care: Prevalence and recognition. British Journal of Psychiatry, 194, 117-122.

Corfield, E. C., Martin, N. G., \& Nyholt, D. R. (2016). Cooccurrence and symptomatology of fatigue and depression. Comprehensive Psychiatry, 71, 1-10.

Eveng Ård, B., Jacks, A., Pedersen, N. L., \& Sullivan, P. F. (2005). The epidemiology of chronic fatigue in the Swedish Twin Registry. Psychological Medicine, 35, 1317-1326.

Farmer, A., Scourfield, J., Martin, N., Cardno, A., \& McGuffin, P. (1999). Is disabling fatigue in childhood influenced by genes? Psychological Medicine, 29, 279-282.

Fowler, T. A., Rice, F., Thapar, A., \& Farmer, A. (2006). Relationship between disabling fatigue and depression in children: Genetic study. British Journal of Psychiatry, 189, 247253.

Friedberg, F., Tintle, N., Clark, J., \& Bromet, E. J. (2015). Prolonged fatigue in Ukraine and the United States: Prevalence and risk factors. Fatigue, 3, 33-46.

Fukuda, K., Straus, S. E., Hickie, I., Sharpe, M. C., Dobbins, J. G., \& Komaroff, A. (1994). The chronic fatigue syndrome: A comprehensive approach to its definition and study. Annals of Internal Medicine, 121, 953-959.

Goldberg, D. P., \& Blackwell, B. (1970). Psychiatric illness in general practice. A detailed study using a new method of case identification. British Medical Journal, 1, 439-443.
Hamaguchi, M., Kawahito, Y., Takeda, N., Kato, T., \& Kojima, T. (2011). Characteristics of chronic fatigue syndrome in a Japanese community population chronic fatigue syndrome in Japan. Clinical Rheumatology, 30, 895-906.

Hickie, I., Bennett, B., Lloyd, A., Heath, A., \& Martin, N. (1999). Complex genetic and environmental relationships between psychological distress, fatigue and immune functioning: A twin study. Psychological Medicine, 29, 269277.

Hickie, I., Kirk, K., \& Martin, N. (1999). Unique genetic and environmental determinants of prolonged fatigue: A twin study. Psychological Medicine, 29, 259-268.

Hickie, I. B., Bansal, A. S., Kirk, K. M., Lloyd, A. R., \& Martin, N. G. (2001). A twin study of the etiology of prolonged fatigue and immune activation. Twin Research, 4, 94-102.

Hickie, I. B., Hooker, A. W., Hadzi-Pavlovic, D., Bennett, B. K., \& Wilson, A. J. (1996). Fatigue in selected primary care settings: Sociodemographic and psychiatric correlates. Medical Journal of Australia, 164, 585-588.

Holmes, G. P., Kaplan, J. E., Gantz, N. M., Komaroff, A. L., Schonberger, L. B., Straus, S. E., ... Brus, I. (1988). Chronic fatigue syndrome: A working case definition. Annals of Internal Medicine, 108, 387-389.

Hur, Y.-M., Burri, A., \& Spector, T. D. (2012). The genetic and environmental structure of the covariation among the symptoms of insomnia, fatigue, and depression in adult females. Twin Research and Human Genetics, 15, 720-726.

Jason, L. A., Richman, J. A., Rademaker, A. W., Jordan, K. M., Plioplys, A. V., Taylor, R. R., ... Plioplys, S. (1999). A community-based study of chronic fatigue syndrome. Archives of Internal Medicine, 159, 2129-2137.

Jason, L. A., Taylor, R., Wagner, L., Holden, J., Ferrari, J. R., Plioplys, A. V., ... Papernik, M. (1995). Estimating rates of chronic fatigue syndrome from a community-based sample: A pilot study. American Journal of Community Psychology, 23, 557-568.

Kato, K., Sullivan, P. F., Evengard, B., \& Pedersen, N. L. (2009). A population-based twin study of functional somatic syndromes. Psychological Medicine, 39, 497-505.

Kawakami, N., Iwata, N., Fujihara, S., \& Kitamura, T. (1998). Prevalence of chronic fatigue syndrome in a community population in Japan. Tohoku Journal of Experimental Medicine, 186, 33-41.

Kendler, K. S. (1993). Twin studies of psychiatric illness. Current status and future directions. Archives of General Psychiatry, 50, 905-915.

Kim, C. H., Shin, H. C., \& Won, C. W. (2005). Prevalence of chronic fatigue and chronic fatigue syndrome in Korea: Community-based primary care study. Journal of Korean Medical Science, 20, 529-534.

Lindal, E., Stefansson, J. G., \& Bergmann, S. (2002). The prevalence of chronic fatigue syndrome in Iceland - A national comparison by gender drawing on four different criteria. Nordic Journal of Psychiatry, 56, 273-277.

Loge, J. H., Ekeberg, O., \& Kaasa, S. (1998). Fatigue in the general Norwegian population: Normative data and associations. Journal of Psychosomatic Research, 45, 53-65. 
Mosing, M. A., Medland, S. E., McRae, A., Landers, J. G., Wright, M. J., \& Martin, N. G. (2012). Genetic influences on life span and its relationship to personality: A 16-year follow-up study of a sample of aging twins. Psychosomatic Medicine, 74, 16-22.

Nacul, L. C., Lacerda, E. M., Pheby, D., Campion, P., Molokhia, M., Fayyaz, S., ... Drachler, M. L. (2011). Prevalence of myalgic encephalomyelitis/chronic fatigue syndrome (ME/CFS) in three regions of England: A repeated crosssectional study in primary care. BMC Medicine, 9, 91-102.

Narusyte, J., Ropponen, A., Alexanderson, K., \& Svedberg, P. (2016). Genetic and environmental influences on disability pension due to mental diagnoses: Limited importance of major depression, generalized anxiety, and chronic fatigue. Twin Research and Human Genetics, 19, 10-16.

Neale, M., \& Cardon, L., (1992). Methodology for genetic studies of twins and families. Dordrecht, the Netherlands: Kluwer Academic Publishers.

Njoku, M. G. C., Leonard, A. J., \& Torres-Harding, S. R. (2007). The prevalence of chronic fatigue syndrome in Nigeria. Journal of Health Psychology, 12, 461-474.

Patel, V., Kirkwood, B., Weiss, H., Pednekar, S., Fernandes, J., Pereira, B., ... Mabey, D. (2005). Chronic fatigue in developing countries: Population based survey of women in India. British Medical Journal, 330, 1190-1193.

R Core Team. (2014). R: A language and environment for statistical computing. Vienna, Austria: R Foundation for Statistical Computing.

Reyes, M., Nisenbaum, R., Hoaglin, D. C., Unger, E. R., Emmons, C., Randall, B., ... Reeves, W. C. (2003). Prevalence and incidence of chronic fatigue syndrome in $\mathrm{Wi}$ chita, Kansas. Archives of Internal Medicine, 163, 15301536.

Schur, E., Afari, N., Goldberg, J., Buchwald, D., \& Sullivan, P. F. (2007). Twin analyses of fatigue. Twin Research and Human Genetics, 10, 729-733.
Steele, L., Dobbins, J. G., Fukuda, K., Reyes, M., Randall, B., Koppelman, M., \& Reeves, W. C. (1998). The epidemiology of chronic fatigue in San Francisco. American Journal of Medicine, 105(3 Part A), 83S-90S.

Sullivan, P. F., Evengard, B., Jacks, A., \& Pedersen, N. L. (2005). Twin analyses of chronic fatigue in a Swedish national sample. Psychological Medicine, 35, 1327-1336.

Sullivan, P. F., Kovalenko, P., York, T. P., Prescott, C. A., \& Kendler, K. S. (2003). Fatigue in a community sample of twins. Psychological Medicine, 33, 263-281.

van de Putte, E. M., van Doornen, L. J., Engelbert, R. H., Kuis, W., Kimpen, J. L., \& Uiterwaal, C. S. (2006). Mirrored symptoms in mother and child with chronic fatigue syndrome. Pediatrics, 117, 2074-2079.

Vincent, A., Brimmer, D. J., Whipple, M. O., Jones, J. F., Boneva, R., Lahr, B. D., ... Reeves, W. C. (2012). Prevalence, incidence, and classification of chronic fatigue syndrome in Olmsted County, Minnesota, as estimated using the Rochester Epidemiology Project. Mayo Clinic Proceedings, 87, 1145-1152.

Walsh, C. M., Zainal, N. Z., Middleton, S. J., \& Paykel, E. S. (2001). A family history study of chronic fatigue syndrome. Psychiatric Genetics, 11, 123-128.

Wessely, S., Chalder, T., Hirsch, S., Pawlikowska, T., Wallace, P., \& Wright, D. J. M. (1995). Postinfectious fatigue Prospective cohort study in primary-care. Lancet, 345, 1333-1338.

Wessely, S., Chalder, T., Hirsch, S., Wallace, P., \& Wright, D. (1997). The prevalence and morbidity of chronic fatigue and chronic fatigue syndrome: A prospective primary care study. American Journal of Public Health, 87, 14491455.

Wong, W. S., \& Fielding, R. (2010). Prevalence of chronic fatigue among Chinese adults in Hong Kong: A populationbased study. Journal of Affective Disorders, 127, 248256. 